\title{
Magnetic Resonance Spectroscopy following Mild Traumatic Brain Injury: A Systematic Review and Meta-Analysis on the Potential to Detect Posttraumatic Neurodegeneration
}

\author{
Amanda Eisele $\mathrm{e}^{\mathrm{a}, \mathrm{b}}$ MaryJane Hill-Strathy ${ }^{\mathrm{a}, \mathrm{c}}$ Lars Michels $^{\mathrm{d}}$ Katrin Rauen ${ }^{\mathrm{a}, \mathrm{e}}$ \\ ${ }^{a}$ Department of Geriatric Psychiatry, Psychiatric Hospital Zurich, University of Zurich, Zurich, Switzerland; \\ ${ }^{\mathrm{b}}$ Department of Neurology, University Hospital Zurich, Zurich, Switzerland; \\ 'School of Psychology and Neuroscience, University of St Andrews, St Andrews, UK; \\ dDepartment of Neuroradiology, University Hospital Zurich, Zurich, Switzerland; \\ e Institute for Regenerative Medicine, University of Zurich, Schlieren, Switzerland
}

\section{Keywords}

Mild traumatic brain injury - Neuronal density/integrity ·

Glutamate - Magnetic resonance spectroscopy .

Posttraumatic neurodegeneration · Metabolites .

$\mathrm{N}$-acetyl-aspartate

\begin{abstract}
Introduction: Traumatic brain injury (TBI) is the most relevant external risk factor for dementia and a major global health burden. Mild TBI (mTBI) contributes to up to $90 \%$ of all TBIs, and the classification "mild" often misrepresents the patient's burden who suffer from neuropsychiatric longterm sequelae. Magnetic resonance spectroscopy (MRS) allows in vivo detection of compromised brain metabolism although it is not routinely used after TBI. Objective: Thus, we performed a systematic review and meta-analysis to elucidate if MRS has the potential to identify changes in brain metabolism in adult patients after a single $\mathrm{mTBI}$ with a negative routine brain scan (CCT and/or MRI scan) compared to aged- and sex-matched healthy controls $(\mathrm{HC})$ during the acute or subacute postinjury phase ( $\leq 90$ days after mTBI). Methods: A comprehensive literature search was conducted
\end{abstract}

karger@karger.com www.karger.com/ndd

Karger $\stackrel{\text { ' }}{5}$

GOPEN ACCESS
(C) 2020 The Author(s)

Published by S. Karger AG, Basel

This is an Open Access article licensed under the Creative Commons Attribution-NonCommercial-4.0 International License (CC BY-NC) (http://www.karger.com/Services/OpenAccessLicense), applicable to the online version of the article only. Usage and distribution for commercial purposes requires written permission. from the first edition of electronic databases until January 31, 2020. Group analyses were performed per metabolite using a random-effects model. Results: Four and 2 out of 5,417 articles met the inclusion criteria for the meta-analysis and systematic review, respectively. For the meta-analysis, 50 mTBI patients and $51 \mathrm{HC}$ with a mean age of 31 and 30 years, respectively, were scanned using $\mathrm{N}$-acetyl-aspartate (NAA), a marker for neuronal integrity. Glutamate (Glu), a marker for disturbed brain metabolism, choline (Cho), a marker for increased cell membrane turnover, and creatine $(\mathrm{Cr})$ were used in 2 out of the 4 included articles. Regions of interests were the frontal lobe, the white matter around $1 \mathrm{~cm}$ above the lateral ventricles, or the whole brain. NAA was decreased in patients compared to $\mathrm{HC}$ with an effect size (ES) of -0.49 $(95 \% \mathrm{Cl}-1.08$ to 0.09$)$, primarily measured in the frontal lobe. Glu was increased in the white matter in $22 \mathrm{mTBI}$ patients compared to $22 \mathrm{HC}$ (ES $0.79 ; 95 \% \mathrm{Cl} 0.17-1.41$ ). Cho was decreased in $31 \mathrm{mTBI}$ patients compared to $31 \mathrm{HC}$ (ES -0.31; $95 \% \mathrm{Cl}-0.81$ to 0.19$)$. Cr was contradictory and, therefore, potentially not suitable as a reference marker after mTBI.

A.E. and M.H.-S. contributed equally to this work.

Katrin Rauen

Department of Geriatric Psychiatry

Psychiatric Hospital Zurich, University of Zurich

Minervastrasse 145, CH-8032 Zurich (Switzerland)

katrin.rauen@uzh.ch 
Conclusions: MRS pinpoints changes in posttraumatic brain metabolism that correlate with cognitive dysfunction and, thus, might possibly help to detect mTBI patients at risk for unfavorable outcome or posttraumatic neurodegeneration early.

(c) 2020 The Author(s)

Published by S. Karger AG, Basel

\section{Introduction}

Traumatic brain injury (TBI) is the most relevant external risk factor for dementia and shares hallmarks of neurodegenerative diseases, such as Alzheimer and Parkinson disease, and frontotemporal dementia [1-3]. Each year, over 50 million people sustain a TBI, which renders TBI the global leading cause of death and disability among the young and working populations. Thus, TBI is a major public health concern with tremendous socioeconomic implications and estimated costs of approximately USD 400 billion annually [4].

Mild TBI (mTBI) accounts for $80-90 \%$ of all brain impacts and is defined according to the American Congress of Rehabilitation Medicine (ACRM) by a score of 13-15 on the Glasgow Coma Scale (GCS), a maximum loss of consciousness of $30 \mathrm{~min}$, and posttraumatic amnesia $<24 \mathrm{~h}$ after the brain injury [5-7]. The term mild TBI often misrepresents the patient's burden with functional, emotional, and cognitive long-term sequelae, as half of mTBI patients with a negative cranial computed tomography (CCT) complain functional limitations 12 months after the brain impact, and up to one third suffer from cognitive dysfunction [8-12]. Nearly $90 \%$ of CCT or routine MRI brain scans remain negative despite major clinical health concerns with the inability to return to work after mTBI [13-17], which emphasizes the need for additional diagnostic tools to identify patients earlier who are at risk for unfavorable outcome or even posttraumatic dementia. Current state-of-the-art CCT and MRI techniques are limited in recognizing the full complexity of the mTBI neuropathology, and thus more sensitive, yet still realistic clinical measures to detect early compromised brain metabolism that might help to predict longterm cognitive deficits are required $[16,18]$.

Magnetic resonance spectroscopy (MRS) allows for in vivo measurement of metabolites that are undetectable by conventional neuroimaging thereby holding potential to identify mTBI patients that could benefit from specific neuropsychiatric and cognitive rehabilitation [19]. Brain energy metabolism is altered after TBI due to posttraumatic ischemia with mitochondrial dysfunction and loss of neuronal integrity with increased cell membrane turnover. In vivo MRS is an MRI technique that can detect nuclei with spins such as ${ }^{1} \mathrm{H}$, an abundant by-product of cellular respiration and brain tissue metabolites. As a noninvasive and safe technique, MRS is available on clinical MR scanners (1.5 and 3.0 T) without ionizing radiation [20]. This method holds the potential to identify compromised brain metabolism, but evidence after mTBI is scarce [21]. Key metabolites such as $\mathrm{N}$-acetyl-aspartate (NAA), glutamate (Glu), and choline (Cho) have the potential to capture the dynamic and fuller picture of the secondary changes occurring in the injured brain, while creatine $(\mathrm{Cr})$ is widely recommended as a reference marker (Table 1). However, its current application in TBI patients is purely analytical [22].

As it stands, there is currently no clinically available objective biological tool for mTBI classification beyond the GCS - albeit a major goal of the large TRACK-TBI and CENTER-TBI trials. Thus, early detection of compromised brain metabolism as marker for cognitive dysfunction or even the risk for posttraumatic dementia would be highly appreciated by clinicians to provide patients and their families with more reliable information, meanwhile creating a standardized protocol for TBI diagnosis $[4,23,24]$. With these conclusions in mind, we performed a systematic review and meta-analysis to elucidate if MRS might be suitable to identify changes in brain metabolism in adult mTBI patients having a negative CCT and/or MRI brain scan during the acute or subacute postinjury phase in comparison to their age- and sexmatched healthy controls (HC).

\section{Materials and Methods}

This systematic review and meta-analysis were performed according to the PRISMA guidelines for systematic reviews and meta-analysis [25, 26]. Eligibility was assessed according to the PICO (patient, intervention, control, outcome) process. We included original data reporting on adult mTBI patients who underwent MRS with an MRI field strength of 1.5 or $3 \mathrm{~T}$ within 90 days after injury (acute and subacute phase) and compared those to age- and sex-matched HC. Outcome measures were MRS metabolites measured in different regions of interests (ROIs). mTBI was defined according to the ACRM as an external head and brain impact with a transient or permanent focal neurological deficit and/or any alteration in quantitative or qualitative consciousness that does not exceed (i) a GCS of 13-15 after the first $30 \mathrm{~min}$, (ii) a loss of consciousness of $30 \mathrm{~min}$, and (iii) posttraumatic amnesia $<24 \mathrm{~h}[5,6]$.

\section{Inclusion and Exclusion Criteria}

We included original, English, and peer-reviewed research articles reporting on controlled studies using MRS in adult patients
Magnetic Resonance Spectroscopy

following Mild Traumatic Brain Injury
Neurodegener Dis 2020;20:2-11 DOI: $10.1159 / 000508098$ 
Table 1. Magnetic resonance spectroscopy (MRS) metabolite characteristics and changes during the acute/chronic stages after TBI [20]

\begin{tabular}{|c|c|c|c|c|c|c|}
\hline Metabolite & $\begin{array}{l}\text { Spectrum } \\
\text { peak, ppm }\end{array}$ & $\begin{array}{l}\text { Normal conc. } \\
\text { range, } \mathrm{mmol} / \mathrm{L}\end{array}$ & Synthesis/precursor molecules & Role in the healthy brain & Acute changes following TBI & Chronic changes following TBI \\
\hline $\begin{array}{l}N \text {-acetyl- } \\
\text { asparate } \\
\text { (NAA) }\end{array}$ & 2.02 & $7.5-17$ & $\begin{array}{l}\text { Asparate }+ \text { acetyl-CoA with L-aspartate } \\
N \text {-acetyltransferase enzyme or } \\
N \text {-acetylaspartylglutamate split by } \\
N \text {-acetylated- } a \text {-linked-aminodipetidase enzyme }\end{array}$ & $\begin{array}{l}\text { Myelin lipid synthesis, } \\
\text { mitochondrial function, } \\
\text { neuronal viability, } \\
\text { osmoregulation }\end{array}$ & $\begin{array}{l}\text { Rapid decrease } 48 \mathrm{~h} \text { after TBI; } \\
\text { disruptions to neuronal NAA occur } \\
\text { due to mitochondrial dysfunction; } \\
\text { increased hydrolysis of NAA to } \\
\text { provide acetate for myelin repair }\end{array}$ & $\begin{array}{l}\text { NAA recovery in less severe injuries within } \\
\text { days after TBI; slow or no recovery in } \\
\text { severely injured brain concomitant with } \\
\text { hypoxia or hypoperfusion and consecutive } \\
\text { irreversible physical and metabolic damage }\end{array}$ \\
\hline $\begin{array}{l}\text { Glutamate } \\
\text { (Glu) }\end{array}$ & 2.3 & $6.0-12.5$ & $\begin{array}{l}\text { Released from vesicles and converted to Gln } \\
\text { and cycled back to neurons in the Glu-Gln } \\
\text { cycle; often measured through MRS as the } \\
\text { combination of both molecules expressed } \\
\text { as the "Glx" signal }\end{array}$ & $\begin{array}{l}\text { Main excitatory } \\
\text { neurotransmitter in the } \\
\text { central nervous system }\end{array}$ & $\begin{array}{l}\text { Elevated Glx signal early after TBI } \\
\text { in occipital gray and parietal white } \\
\text { matter }\end{array}$ & $\begin{array}{l}\text { Acute increase in Glu levels correlated with } \\
\text { poorer long-term outcome } 6-12 \text { months } \\
\text { after TBI }\end{array}$ \\
\hline $\begin{array}{l}\text { Choline } \\
\text { (Cho) }\end{array}$ & 3.24 & $0.5-2.5$ & $\begin{array}{l}\text { Free choline }+ \text { phosphocholine }+ \\
\text { glycerophosphocholine }\end{array}$ & $\begin{array}{l}\text { Marker for cell membrane } \\
\text { turnover or cell destruction } \\
\text { in aggressive brain tumors } \\
\text { and neurodegenerative } \\
\text { diseases }\end{array}$ & $\begin{array}{l}\text { Increased levels due to cellular } \\
\text { damage and membrane loss }\end{array}$ & $\begin{array}{l}\text { Cho levels remain elevated up to } 3 \text { months } \\
\text { after moderate/severe TBI. Increased Cho } \\
\text { levels during the acute phase correlated with } \\
\text { poorer long-term outcome at } 6-12 \text { months }\end{array}$ \\
\hline $\begin{array}{l}\text { Creatine } \\
(\mathrm{Cr})\end{array}$ & 3.02 & $\mathrm{n} / \mathrm{a}^{\mathrm{a}}$ & Phosphorylated from phosphocreatine (PCr) & $\begin{array}{l}\text { Marker for brain energy } \\
\text { metabolism, ATP synthesis, } \\
\text { and regeneration }\end{array}$ & $\begin{array}{l}\text { Consensus that it remains at stable } \\
\text { levels following TBI, and thus used } \\
\text { as a reference in metabolite ratios }\end{array}$ & $\mathrm{n} / \mathrm{a}^{\mathrm{b}}$ \\
\hline
\end{tabular}

( $\geq 18$ years) having experienced a single mTBI (ACMR criteria) during the acute or subacute phase after the brain impact. Data were included from patients with no clinical need for a brain scan or with a negative CCT or MRI. At least 1 of the following metabolites or metabolite ratios had to be measured: NAA, Cho, Glu, Cr, glutamine (Gln), myoinositol (mIns), NAA/Cr, Cho/Cr, Glx (Glu/ $\mathrm{Gln}) / \mathrm{Cr}$, and $\mathrm{mIns} / \mathrm{Cr}$. Exclusion criteria were any brain pathology in a CCT and/or MRI scan, MRS performed beyond 90 days after TBI, children, patients with repetitive concussions with a previous TBI or any premorbidly diagnosed neurobehavioral (e.g., depression or bipolar disorder) or neurological comorbidity (e.g., seizures and brain tumors), non-peer-reviewed articles, conference abstracts, case reports, book chapters, non-controlled studies, interventional studies, animal studies, and non-English language articles.

\section{Search and Data Selection}

A comprehensive literature search was conducted from the first edition of electronic databases until January 31, 2020, specifically through PubMed (1901 to present), ScienceDirect (2000 to present), Cochrane Library (1991 to present), and Scopus (1980 to present; Fig. 1). Relevant reviews and their supplementary material were included in full-text screening to check analyzed studies for eligibility as well as their reference lists to ensure that the most possible studies were identified. Search terms are available in the online supplementary Table S1 (for all online suppl. material, see www.karger.com/doi/10.1159/000508098). After removing duplicates, all articles were screened independently in a blinded standardized manner by 2 reviewers (A.E. and M.H.-S.). Disagreements on inclusion between reviewers were resolved for final decision through a detailed discussion and an additional reviewer (K.R.).

\section{Risk of Bias Assessment}

A risk of bias assessment was performed using a modified version of the ROBINS-I tool [27]. Evaluation of confounding, selection, classification of intervention(s), missing data, measurement of outcome(s), and selection of the reported result biases were assessed with either low, high, or unclear risk judgments, and the GRADE assessment was used to evaluate the level of evidence across included studies [28].

\section{Statistical Analysis}

Demographic data (sex and age) and basic characteristics (MRS time point after TBI, metabolites, ROIs, and MRI field strengths) are presented, and data are given as means \pm SD and/or ranges. For the meta-analysis, metabolites were analyzed if applied in at least 2 out of the 4 included studies. Statistical analysis and graphs were performed using Review Manager Software 5.3 (Copenhagen, Denmark) and R (R Core Team, Vienna, Austria), respectively [29]. Effect size (ES) and 95\% confidence intervals (CIs) of each defined MRS metabolite (Table 1), namely NAA, Glu, Cho, and Cr, were calculated using a random-effects model according to DerSimonian and Laird [30].

\section{Results}

The database search returned 5,395 articles and further 22 articles were identified from relevant reviews or reference lists (Fig. 1). After removing duplicates, 5,276 articles were screened by title and abstract. Thereafter, 94 full-text articles were assessed for eligibility. Two articles were eligible for the systematic review, below indicated as study 1 by Gasparovic et al. [24] and as study 2 by Sivák et al. [31], and 4 articles were eligible for the meta-analysis, namely study 1 [24], study 2 [31], study 3 by Veeramuthu et al. [32], and study 4 by Cohen et al. [33]. Studies 3 and 4 were not eligible for the systematic review $[32,33]$ due to the lack of subgroup analysis of CCT-negative patients. 


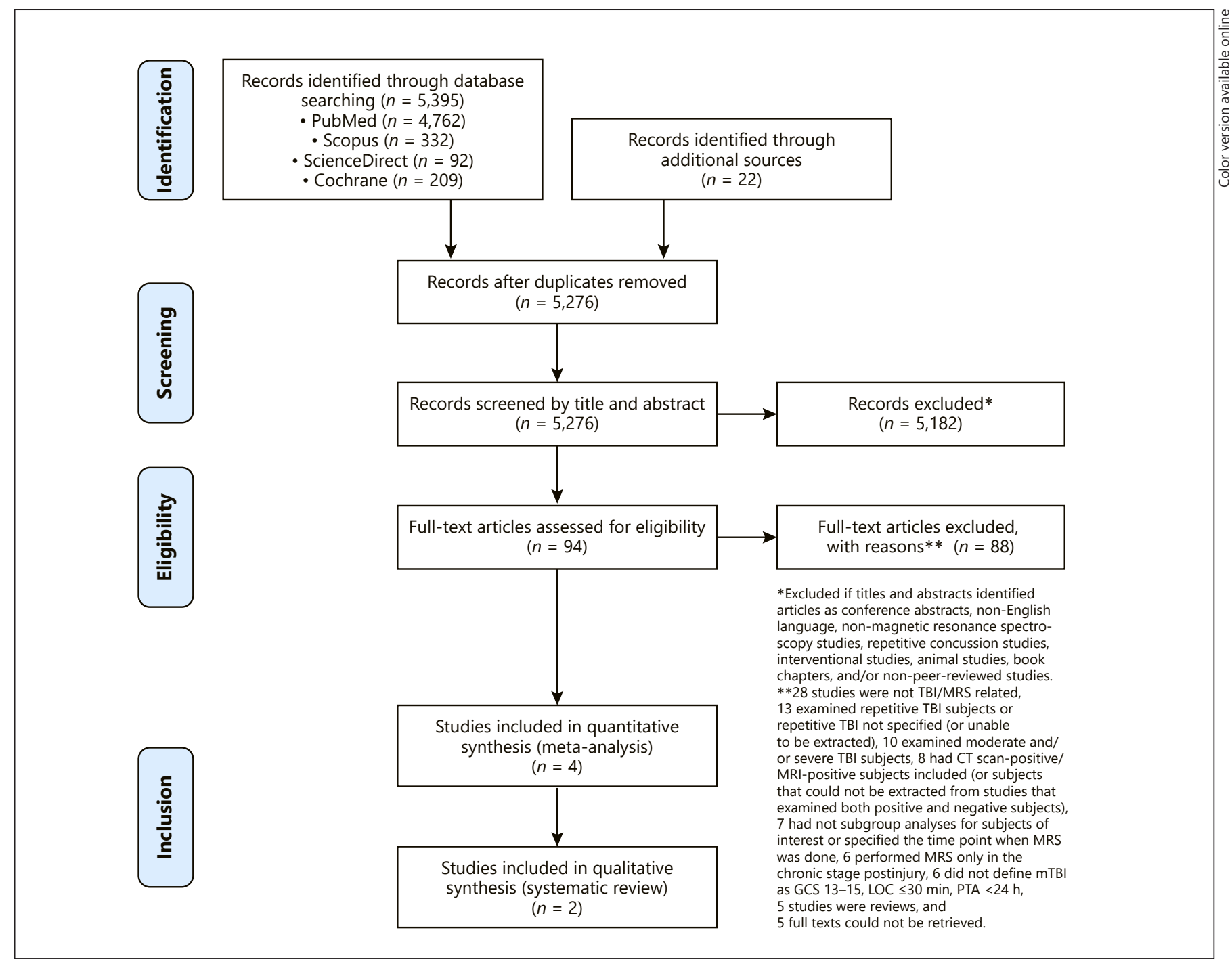

Fig. 1. PRISMA flowchart depicting included full-text articles. Two and 4 out of 94 full-text articles were included in the systematic review and meta-analysis, respectively.

\section{Systematic Review}

The 2 included studies analyzed a total of $31 \mathrm{mTBI}$ patients ( 23 males, 8 females) and 31 sex- and aged-matched HC ( 24 males, 7 females) with a mean age of 31 and 30 years, respectively (Table 2). The mean time between TBI and MRS was 6.4 days (range 2.7-19 days). Metabolites quantified in both studies were NAA or NAA + NAA glutamate, NAA/Cr, Cho, and Cr. Authors analyzed the following ROIs: study 1 investigated (i) the white matter (WM) between anterior cingulum, medial frontal gyrus, and superior longitudinal fasciculus, (ii) gray matter (GM) in the interhemispheric fissure, and (iii) the splenium, while study 2 analyzed (iv) the right frontal lobe, (v) the left frontal lobe, and (vi) the pons (Table 2).
Gasparovic et al. [24] (study 1) found a nonsignificant Cho change in different ROIs. In detail, Cho was slightly increased compared to $\mathrm{HC}$ in the interhemispheric fissure (GM) and in the splenium, whereas it was decreased in the WM, that is, $1 \mathrm{~cm}$ above the lateral ventricles. $\mathrm{Cr}$ was significantly increased in the WM and splenium, and nonsignificantly decreased in the GM. Glx was significantly decreased in the GM, and nonsignificantly increased in the WM. No significant effect was seen for NAA in the above-mentioned ROIs and time points, namely 3-19 days after mTBI.

Sivák et al. [31] (study 2) observed a significantly lower NAA concentration in the right and left frontal lobes. Lower NAA/Cr and Cho/Cr ratios were found in the right 

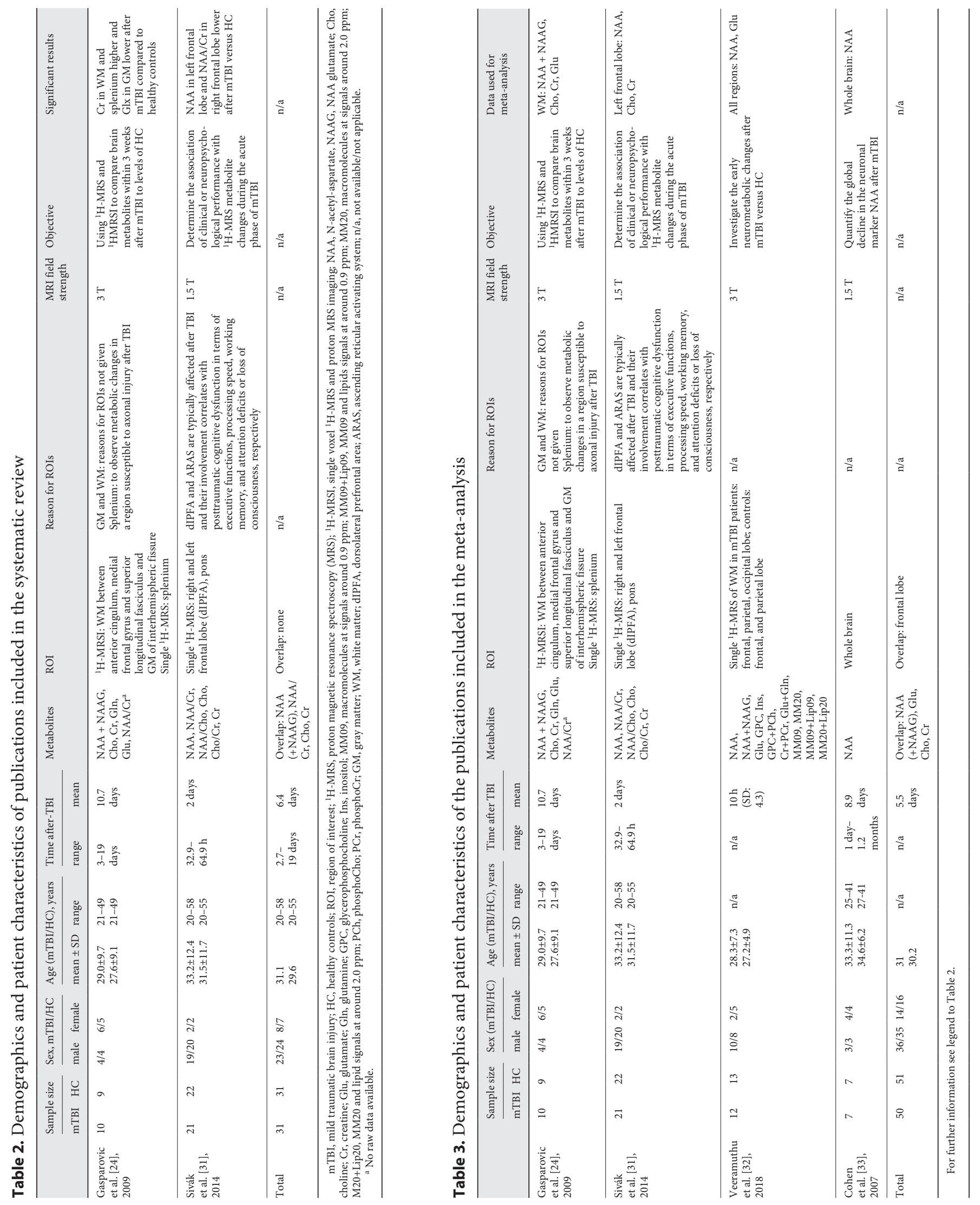
Fig. 2. $N$-acetyl-aspartate (NAA) is a marker for neuronal density and integrity. NAA moderately decreases after mTBI in comparison to $\mathrm{HC}$ with an overall ES of -0.49 (95\% CI -1.08 to 0.09 ), thus representing a moderate effect. NAA was analyzed in the WM $1 \mathrm{~cm}$ above the lateral ventricles (study 1), in the left frontal lobe (study 2), or in all brain regions (studies 3 and 4). Sivák et al. [31] (study 2) compared 21 mTBI patients to $22 \mathrm{HC}$ and elucidated a significant decrease in NAA $(p=0.002)$ in the left frontal lobe when measured 2 days (mean) after mTBI.

Fig. 3. Glutamate (Glu) is a marker for disturbed brain metabolism. Two out of the 4 included studies (studies 1 and 3) measured increased Glu in the WM $1 \mathrm{~cm}$ above the lateral ventricles at $10 \mathrm{~h}$ (mean) and in the whole brain 10.7 days (mean) after mTBI, respectively. The overall effect size was strong with 0.79 (95\% CI 0.17-1.41).

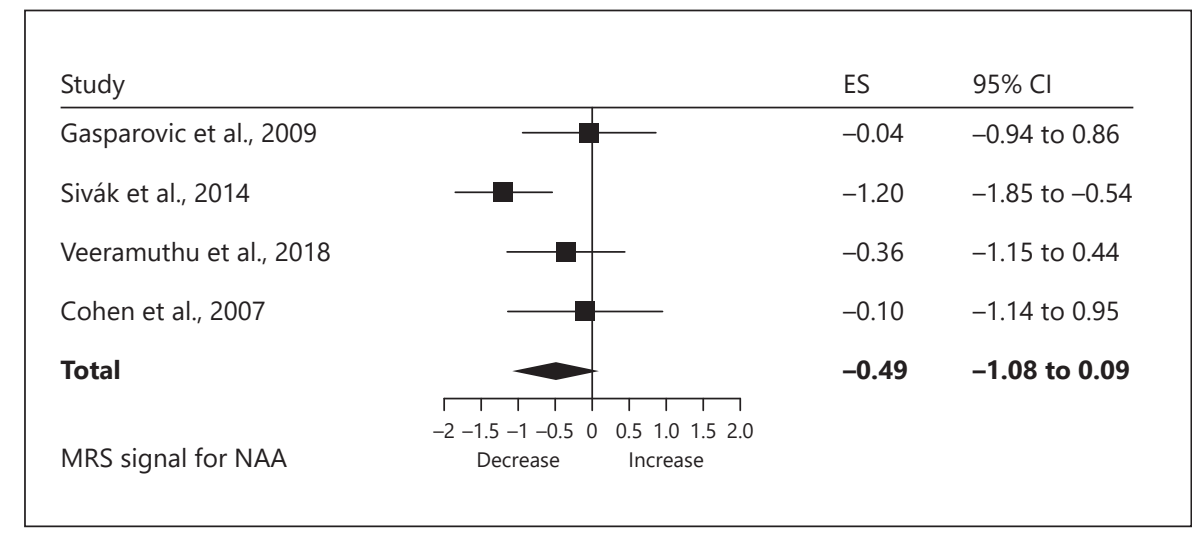

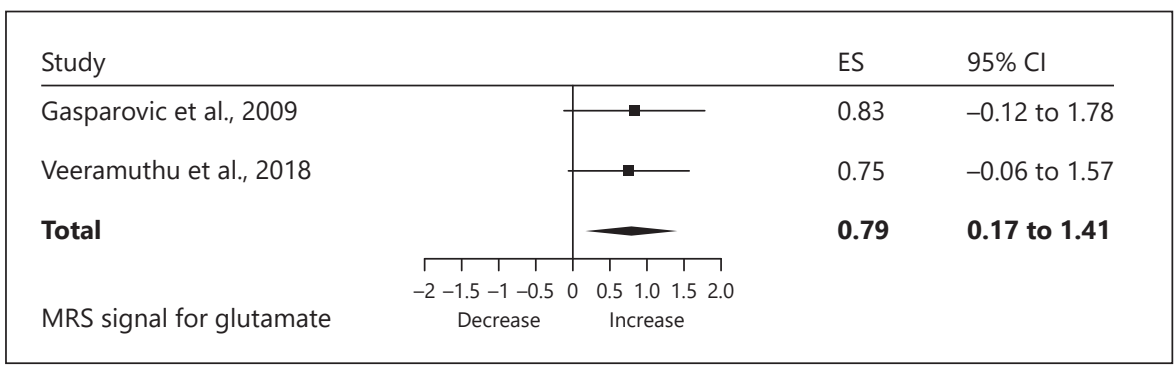

frontal lobe. After Bonferroni's adjustment to correct for multiple comparisons, NAA in the left frontal lobe and $\mathrm{NAA} / \mathrm{Cr}$ in the right frontal lobe remained significantly lower in patients after mTBI compared to HC. Absolute Cho and $\mathrm{Cr}$ concentrations in the left frontal lobe tended to be lower in mTBI patients.

\section{Meta-Analysis}

Four studies were included in the meta-analysis analyzing $50 \mathrm{mTBI}$ patients ( 36 males, 14 females) and $51 \mathrm{HC} \mathrm{(35}$ males, 16 females) with a mean age of 31 and 30 years, respectively. Patients received MRS 5.5 days (mean) after the brain impact (Table 3). Of study 3 [32] a subgroup of CCTnegative mTBI patients $(n=12)$ and of study 4 [33] a subgroup of $7 \mathrm{mTBI}$ and $\mathrm{HC}$ were eligible for inclusion. ROIs and their rationales as well as metabolites are detailed in Table 3. Study 2 analyzed the left and right frontal lobes separately, of which we used the data from the left frontal lobe and thereby avoided an overrepresented analysis [31]. Regarding measured metabolites, NAA was analyzed across all 4 studies, while Glu, Cho, and Cr overlapped in 2 out of the 4 studies. MRS sequences, the localization of voxel placement, and voxel sizes differed across all 4 studies or were not given. Studies 1-3 used the PRESS sequence. Study 4 used nonlocalizing proton MRS. Voxel sizes or vol-

Magnetic Resonance Spectroscopy

following Mild Traumatic Brain Injury umes were $1 \times 1 \times 1 \mathrm{~cm}$ (study 1$), 12 \mathrm{~mL}$ (cortex), and 9 $\mathrm{mL}$ (upper brainstem) (study 2), $19 \times 19 \times 19 \mathrm{~mm}$ (study 3 ), or were not specified (study 4 ). Within and across studies, risk of bias was low (online suppl. Table S2).

\section{N-Acetyl-Aspartate/N-Acetyl-Aspartyl-Glutamate}

Across all 4 studies, NAA showed a moderate decline with a moderate overall ES of -0.49 (95\% CI -1.08 to 0.09 ) in $50 \mathrm{mTBI}$ patients compared to $51 \mathrm{HC}$ (Fig. 2). This result was mainly based on the findings of study 2 , in which NAA was analyzed in the left frontal lobe in $21 \mathrm{mTBI}$ patients (ES $-1.2 ; 95 \% \mathrm{CI}-1.85$ to -0.54 ). In studies 1,3 , and 4 , there were no significant differences in NAA concentrations between mTBI patients and HC.

\section{Glutamate}

Studies 1 and 3 found increased Glu, which was primarily measured in the WM of the parietal lobe in mTBI patients compared to $\mathrm{HC}$ with an overall strong ES of 0.79 (95\% CI 0.17-1.41; Fig. 3).

\section{Choline}

Studies 1 and 2 reported on decreased Cho in mTBI patients with a weak overall ES of -0.31 ( $95 \%$ CI -0.81 to 0.19; Fig. 4). 
Fig. 4. Choline (Cho) is a marker for increased cell membrane turnover, and increased levels in MRS detect cellular damstudies (studies 1 and 2) measured increased Cho in the WM $1 \mathrm{~cm}$ above the lateral ventricles at $10 \mathrm{~h}$ (mean) and in the left frontal lobe 2 days (mean) after mTBI, respectively. The overall effect size was moderate with -0.31 (95\% CI -0.81 to 0.19$)$. age after mTBI. Two out of the 4 included

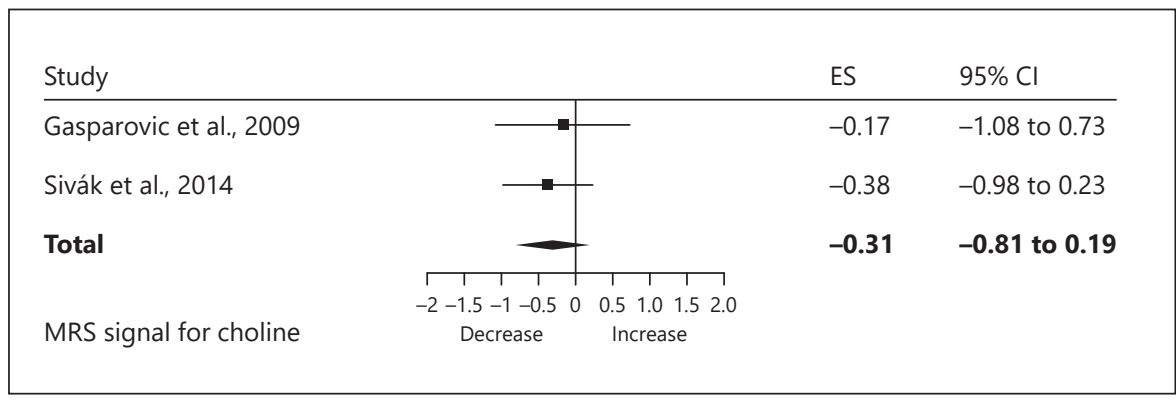

Fig. 5. Creatine $(\mathrm{Cr})$ is currently suggested as a reference marker for MRS. Two out of the 4 included studies (studies 1 and 2) measured contradictory $\mathrm{Cr}$ results in the WM $1 \mathrm{~cm}$ above the lateral ventricles $10 \mathrm{~h}$ (mean) and in the left frontal lobe 10.7 days (mean) after mTBI, respectively. The overall effect size was very low -0.01 (95\% CI -1.59 to 1.58 ), which suggests that $\mathrm{Cr}$ is not a suitable reference marker after mTBI.

\begin{tabular}{|c|c|c|c|c|}
\hline Study & & & ES & $95 \% \mathrm{Cl}$ \\
\hline Gasparovic et al., 2009 & & $\longrightarrow$ & 0.84 & -0.11 to 1.79 \\
\hline Sivák et al., 2014 & $\longrightarrow$ & & -0.77 & -1.40 to -0.15 \\
\hline Total & & & -0.01 & -1.59 to 1.58 \\
\hline MRS signal for creatine & 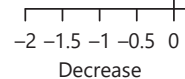 & \begin{tabular}{l|llll} 
& 1 & 1 & \\
0.5 & 1.0 & 1.5 & 2.0 \\
Increase
\end{tabular} & & \\
\hline
\end{tabular}

\section{Creatine}

Study 1 showed a significant increase in $\mathrm{Cr}$, which was measured in the WM, that is, $1 \mathrm{~cm}$ above the lateral ventricles with an ES of 0.84 (95\% CI -0.11 to 1.79; Fig. 5). Study 2 reported a nonsignificant $\mathrm{Cr}$ decrease in the left frontal lobe with an ES of -0.77 (95\% CI -1.4 to -0.15 ). These contradictory results led to an overall ES for $\mathrm{Cr}$ of -0.01 (95\% CI -1.59 to 1.58$)$.

\section{Discussion}

In this systematic review and meta-analysis, 2 and 4 out of 5,417 identified records were included, respectively. The most crucial findings were alterations in NAA and Glu concentrations using MRS at 3 or $1.5 \mathrm{~T}$ within 90 days after injury, i.e., during the acute and subacute phase after a single $\mathrm{mTBI}$ in adults having a CCT/MRI-negative brain scan. Precisely, lowered NAA and increased Glu concentrations were found in $\mathrm{mTBI}$ patients compared to HC, indicative for loss of neuronal integrity and disturbed brain metabolism $[20,24,34]$. Cho slightly decreased in mTBI patients, which differs to the amplified Cho concentrations in patients with neurodegenerative diseases and brain tumors as a hallmark of cell membrane turnover [20]. In contrast, there is evidence that Cho increases over time when measured in the WM but not in the GM up to 55 days after mTBI [35], which indicates that the axonal pathology and precise definitions of where and when to measure metabolites are needed. However, the relevance of the overall decreased Cho measured in the GM and WM within study 1 and 2 during the acute and subacute phase after mTBI remains unclear and might be associated to the function of Cho as a precursor molecule for myelin. Thus, we suggest to repetitively measure Cho to elucidate its function over time after mTBI. Results on $\mathrm{Cr}$ concentrations in mTBI patients were contradictory and potentially attributed to different field strengths and ROIs. Moreover, a recent longitudinal study demonstrated that higher Cr levels in the subacute stage were positively correlated to cognitive impairment during the chronic stage after mTBI when measured in the centrum semiovale, thus in the WM [36]. Kirov et al. [35] found increasing Cr levels over time when measured in the WM but not in the GM up to 55 days after mTBI, which again emphasizes the axonal pathology after mTBI. In summary, it remains doubtful that $\mathrm{Cr}$ is a suitable reference marker following $\mathrm{mTBI}$ as previously suggested [20].

When interpreting the current results, different time points of MRS after mTBI must be considered especially as the results of NAA and Cho are mainly driven by study 2 (Sivák et al. [31]), which measured brain metabolites within 33-64 h after mTBI. Thus, early MRS after mTBI could be favorable in detecting relevant metabolic changes, and we suggest bearing this in mind for future investigations. 
We chose strict inclusion criteria investigating mTBI patients with negative routine brain scans that are often underdiagnosed yet still exhibit posttraumatic symptoms [37]. Early diagnosis of those presumably mildly braininjured patients at risk for long-term consequences is critically relevant as longitudinal follow-up studies underline continued symptoms, including chronic fatigue, psychiatric disorders, and unsatisfied quality of life in one third of patients [38-41]. A recent meta-analysis revealed that MRS might have limitations for use in mTBI patients [21], which is contradictory to our findings possibly due to a greater heterogeneity of their study population. In detail, this meta-analysis defined broader inclusion criteria analyzing mTBI not strictly using the ACMR guidelines and additionally included postconcussion patients during the acute, subacute, or chronic phase with or without positive brain scans. This meta-analysis found no brain metabolite changes in these mixed mTBI and postconcussion patients [21], most probably accentuating the different pathophysiology after concussion and single mTBI.

Integrating the current evidence, there is a need for standardized temporal and spatial MRS protocols for future research of mTBI patients.

\section{MRS and the Link to Neurodegeneration}

MRS exploits metabolic alterations in neurodegenerative diseases and brain tumors [42-45], but evidence following mTBI is sparse. Animal studies using MRS after experimental TBI suggest Gln, pyruvate, glycerol, and phosphocholine as suitable metabolites to detect diffuse axonal injury and posttraumatic neurodegeneration [4650]. However, patients with early signs of dementia have exhibited reductions in Glu and NAA [51], suggesting that these metabolic alterations are not specific for TBI, but might point to the posttraumatic pathway and link to neurodegeneration. Moreover, NAA, Glx, and mIns correlated with cognitive outcomes in pediatric TBI patients of all severities [52]. Repetitive sport-related concussions result in chronic neuroinflammation and neurodegeneration, and MRS was previously suggested as a potential biomarker to detect those neurometabolic changes and cognitive impairment [53-57]. Microglial activation and chronic neuroinflammation are discussed as triggers for posttraumatic neurodegeneration $[3,58-60]$, and mIns, a metabolite involved in osmoregulation and astrocyte activity, was elevated after mTBI and thus might be a promising marker [61]. Moreover, future studies should focus on the evident metabolic changes in $\mathrm{mIns}$, $\mathrm{mIns} / \mathrm{Cr}$, and $\mathrm{Glx} / \mathrm{Cr}$ in the putamen and, thus, in the deep GM not only

Magnetic Resonance Spectroscopy

following Mild Traumatic Brain Injury involved in motor but also in cognitive and emotional circuits, particularly working memory, cognitive control, category learning, and emotional control, functions often hampered after mTBI [61].

\section{ROIs following TBI}

Our systematic review and meta-analysis brought up the heterogeneity of analyzed ROIs following $\mathrm{mTBI}$ as the only overlapping ROI was the frontal lobe in 3 out of the 4 studies. In study 2, we included data of the left frontal lobe where NAA was most significantly decreased, and the hampered brain metabolism negatively correlated with neuropsychological performance [31]. Animal studies using MRS following experimental mTBI suggest that the most significant axonal damage is observed in the hippocampus, thalamus, internal capsule, and corpus callosum as early as $2 \mathrm{~h}$ after injury [62]. Thus, we suggest these brain regions to be considered in future trials for standardized ROIs after mTBI. To date, it is difficult to draw conclusions from MRS studies because ROIs are not precisely defined and often do not focus on WM well known to be the pathological hallmark of diffuse axonal injury that causes attentional and cognitive deficits after TBI [45].

\section{Limitations}

A limited number of articles with small sample sizes were eligible for inclusion. Furthermore, MRI sequences, field strength, voxel placements, and sizes were incongruent between studies, and Cramer Rao Lower bounds cutoffs were only given in study 3 . This is necessary as a good signal depends mostly on voxel size, depth, and on the ROI (e.g., signals are less clear at borders with cerebrospinal fluid or air).

\section{Conclusion}

The strongest evidence of metabolic changes was found for decreased NAA and elevated Glu concentrations during the acute to subacute phase in adult mTBI patients compared to $\mathrm{HC}$, while $\mathrm{Cr}$ might be not suitable as a reference marker in mTBI patients. If these metabolites have the capacity to recognize patients with negative routine brain scans that are at risk for posttraumatic longterm sequelae is still not yet clear. Follow-up studies correlating MRS with cognitive outcome are necessary to elucidate the potential of these metabolites as biomarkers to predict and detect posttraumatic neurodegeneration at an early stage. 


\section{Statement of Ethics}

This systematic review and meta-analysis were performed according to the PRISMA guidelines for systematic reviews and meta-analysis. Ethical approval for the literature search was not required.

\section{Disclosure Statement}

The authors declare no conflicts of interests.

\section{Funding Sources}

There are no funding sources to declare.

\section{Author Contributions}

A.E. and M.H.-S. contributed equally to data collection, analysis, interpretation, and writing of the manuscript. L.M. provided technical expertise on the MRS topic and helped revise the manuscript. K.R. designed and supervised the entire systematic review and meta-analysis, helped in decision making for study inclusion, and wrote and revised the manuscript. All authors approved the final version of the manuscript.

\section{References}

1 Smith DH, Johnson VE, Stewart W. Chronic neuropathologies of single and repetitive TBI: substrates of dementia? Nat Rev Neurol. 2013 Apr;9(4):211-21.

2 Washington PM, Villapol S, Burns MP. Polypathology and dementia after brain trauma: does brain injury trigger distinct neurodegenerative diseases, or should they be classified together as traumatic encephalopathy? Exp Neurol. 2016 Jan;275(Pt 3):381-8.

3 Jawaid A, Rademakers R, Kass JS, Kalkonde Y, Schulz PE. Traumatic brain injury may increase the risk for frontotemporal dementia through reduced progranulin. Neurodegener Dis. 2009;6(5-6):219-20.

4 Maas AI, Menon DK, Adelson PD, Andelic N, Bell MJ, Belli A, et al.; InTBIR Participants and Investigators. Traumatic brain injury: integrated approaches to improve prevention, clinical care, and research. Lancet Neurol. 2017 Dec;16(12):987-1048.

5 Kay T, Harrington DE, Adams R, Anderson T, Berrol S. Definition of mild traumatic brain injury. J Head Trauma Rehabil. 1993;8:86-7.

6 Management of Concussion/mTBI Working Group. VA/DoD Clinical Practice Guideline for Management of Concussion/Mild Traumatic Brain Injury. J Rehabil Res Dev. 2009; 46:Cp1-68.

7 Sussman ES, Pendharkar AV, Ho AL, Ghajar J. Mild traumatic brain injury and concussion: terminology and classification. Handb Clin Neurol. 2018;158:21-4.

8 Kashluba S, Hanks RA, Casey JE, Millis SR. Neuropsychologic and functional outcome after complicated mild traumatic brain injury. Arch Phys Med Rehabil. 2008 May;89(5): 904-11.

9 Nelson LD, Temkin NR, Dikmen S, Barber J, Giacino JT, Yuh E, et al.; and the TRACK-TBI Investigators; MIS. Recovery After Mild Traumatic Brain Injury in Patients Presenting to US Level I Trauma Centers: A Transforming Research and Clinical Knowledge in Traumatic Brain Injury (TRACK-TBI) Study. JAMA Neurol. 2019 Jun;76(9):1049.
10 Newcombe VF, Menon DK. Cognitive deficits and mild traumatic brain injury. BMJ. 2013 Mar;346 mar11 1:f1522.

11 van der Naalt J, Timmerman ME, de Koning ME, van der Horn HJ, Scheenen ME, Jacobs $\mathrm{B}$, et al. Early predictors of outcome after mild traumatic brain injury (UPFRONT): an observational cohort study. Lancet Neurol. 2017 Jul;16(7):532-40.

12 Pattinson CL, Gill JM. Risk of dementia after TBI - a cause of growing concern. Nat Rev Neurol. 2018 Sep;14(9):511-2.

13 Bazarian JJ, Zhong J, Blyth B, Zhu T, Kavcic V, Peterson D. Diffusion tensor imaging detects clinically important axonal damage after mild traumatic brain injury: a pilot study. J Neurotrauma. 2007 Sep;24(9):1447-59.

14 Hofman PA, Stapert SZ, van Kroonenburgh MJ, Jolles J, de Kruijk J, Wilmink JT. MR imaging, single-photon emission CT, and neurocognitive performance after mild traumatic brain injury. AJNR Am J Neuroradiol. 2001 Mar;22(3):441-9.

15 Hughes DG, Jackson A, Mason DL, Berry E, Hollis S, Yates DW. Abnormalities on magnetic resonance imaging seen acutely following mild traumatic brain injury: correlation with neuropsychological tests and delayed recovery. Neuroradiology. 2004 Jul;46(7):550-8.

16 Lee $\mathrm{H}$, Wintermark $\mathrm{M}$, Gean $\mathrm{AD}$, Ghajar J, Manley GT, Mukherjee P. Focal lesions in acute mild traumatic brain injury and neurocognitive outcome: CT versus 3T MRI. J Neurotrauma. 2008 Sep;25(9):1049-56.

17 Toth A. Magnetic resonance imaging application in the area of mild and acute traumatic brain injury: Implications for diagnostic markers? Brain Neurotrauma: Molecular. Neuropsychological, and Rehabilitation Aspects; 2015. pp. 329-40.

18 Tavender EJ, Bosch M, Green S, O'Connor D, Pitt V, Phillips K, et al. Quality and consistency of guidelines for the management of mild traumatic brain injury in the emergency department. Acad Emerg Med. 2011 Aug; $18(8): 880-9$.
19 Signoretti S, Lazzarino G, Tavazzi B, Vagnozzi R. The pathophysiology of concussion. PM R. 2011 Oct;3(10 Suppl 2):S359-68.

20 Stovell MG, Yan JL, Sleigh A, Mada MO, Carpenter TA, Hutchinson PJ, et al. Assessing Metabolism and Injury in Acute Human Traumatic Brain Injury with Magnetic Resonance Spectroscopy: Current and Future Applications. Front Neurol. 2017 Sep;8:426.

21 Brown M, Baradaran H, Christos PJ, Wright D, Gupta A, Tsiouris AJ. Magnetic resonance spectroscopy abnormalities in traumatic brain injury: A meta-analysis. J Neuroradiol. 2018 Mar;45(2):123-9.

22 Dager SR, Corrigan NM, Richards TL, Posse S. Research applications of magnetic resonance spectroscopy to investigate psychiatric disorders. Top Magn Reson Imaging. 2008 Apr;19(2):81-96.

23 Saatman KE, Duhaime AC, Bullock R, Maas AI, Valadka A, Manley GT; Workshop Scientific Team and Advisory Panel Members. Classification of traumatic brain injury for targeted therapies. J Neurotrauma. 2008 Jul; 25(7):719-38.

24 Gasparovic C, Yeo R, Mannell M, Ling J, Elgie R, Phillips J, et al. Neurometabolite concentrations in gray and white matter in mild traumatic brain injury: an $1 \mathrm{H}$-magnetic resonance spectroscopy study. J Neurotrauma. 2009 Oct;26(10):1635-43.

25 Moher D, Liberati A, Tetzlaff J, Altman DG; PRISMA Group. Preferred reporting items for systematic reviews and meta-analyses: the PRISMA statement. BMJ. 2009 Jul;339:b2535.

26 Liberati A, Altman DG, Tetzlaff J, Mulrow C Gøtzsche PC, Ioannidis JP, et al. The PRISMA statement for reporting systematic reviews and meta-analyses of studies that evaluate health care interventions: explanation and elaboration. J Clin Epidemiol. 2009 Oct;62(10):e1-34.

27 Sterne JA, Hernán MA, Reeves BC, Savović $\mathrm{J}$, Berkman ND, Viswanathan $\mathrm{M}$, et al. ROBINS-I: a tool for assessing risk of bias in non-randomised studies of interventions. BMJ. 2016 Oct;355:i4919. 
28 Andrews JC, Schünemann HJ, Oxman AD, Pottie K, Meerpohl JJ, Coello PA, et al. GRADE guidelines: 15. Going from evidence to recommendation-determinants of a recommendation's direction and strength. J Clin Epidemiol. 2013 Jul;66(7):726-35.

293 RMR. Review Manager (RevMan). 5.3 ed. Copenhagen: The Nordic Cochrane Centre, The Cochrane Collaboration; 2014.

30 DerSimonian R, Laird N. Meta-analysis in clinical trials. Control Clin Trials. 1986 Sep; 7(3): 177-88.

31 Sivák Š, Bittšanský M, Grossmann J, Nosál' V, Kantorová E, Siváková J, et al. Clinical correlations of proton magnetic resonance spectroscopy findings in acute phase after mild traumatic brain injury. Brain Inj. 2014;28(3): 341-6.

32 Veeramuthu V, Seow P, Narayanan V, Wong JH, Tan LK, Hernowo AT, et al. Neurometabolites Alteration in the Acute Phase of Mild Traumatic Brain Injury (mTBI): An In Vivo Proton Magnetic Resonance Spectroscopy (1H-MRS) Study. Acad Radiol. 2018 Sep;25(9):1167-77.

33 Cohen BA, Inglese M, Rusinek H, Babb JS, Grossman RI, Gonen O. Proton MR spectroscopy and MRI-volumetry in mild traumatic brain injury. AJNR Am J Neuroradiol. 2007 May;28(5):907-13.

34 Moffett JR, Ross B, Arun P, Madhavarao CN, Namboodiri AM. N-Acetylaspartate in the CNS: from neurodiagnostics to neurobiology. Prog Neurobiol. 2007 Feb;81(2):89-131.

35 Kirov II, Tal A, Babb JS, Lui YW, Grossman RI, Gonen O. Diffuse axonal injury in mild traumatic brain injury: a 3D multivoxel proton MR spectroscopy study. J Neurol. 2013 Jan;260(1):242-52.

36 George EO, Roys S, Sours C, Rosenberg J, Zhuo J, Shanmuganathan K, et al. Longitudinal and prognostic evaluation of mild traumatic brain injury: A $1 \mathrm{H}$-magnetic resonance spectroscopy study. J Neurotrauma. 2014 Jun; 31(11):1018-28.

37 Ware JB, Jha S. Balancing underdiagnosis and overdiagnosis: the case of mild traumatic brain injury. Acad Radiol. 2015 Aug;22(8): 1038-9.

38 Shetty T, Nguyen JT, Cogsil T, Tsiouris AJ, Niogi SN, Kim EU, et al. Clinical Findings in a Multicenter MRI Study of Mild TBI. Front Neurol. 2018 Oct;9:836.

39 Zumstein MA, Moser M, Mottini M, Ott SR, Sadowski-Cron C, Radanov BP, et al. Longterm outcome in patients with mild traumatic brain injury: a prospective observational study. J Trauma. 2011 Jul;71(1):120-7.
40 von Wild KR; Hannover, Münster TBI Study Council. Posttraumatic rehabilitation and one year outcome following acute traumatic brain injury (TBI): data from the well defined population based German Prospective Study 2000-2002. Acta Neurochir Suppl (Wien). 2008; 101:55-60.

41 Rauen K, Reichelt L, Probst P, Schäpers B, Müller F, Jahn J, et al. Quality of life up to 10 years after traumatic brain injury: a cross-sectional analysis. Health Qual Life Outcomes. 2020 Jun;18(1): 166.

42 Garnett MR, Blamire AM, Corkill RG, Cadoux-Hudson TA, Rajagopalan B, Styles P. Early proton magnetic resonance spectroscopy in normal-appearing brain correlates with outcome in patients following traumatic brain injury. Brain. 2000 Oct; 123(Pt 10): 2046-54.

43 Garnett MR, Blamire AM, Rajagopalan B, Styles P, Cadoux-Hudson TA. Evidence for cellular damage in normal-appearing white matter correlates with injury severity in patients following traumatic brain injury: A magnetic resonance spectroscopy study. Brain. 2000 Jul;123(Pt 7):1403-9.

44 Vagnozzi R, Signoretti S, Cristofori L, Alessandrini F, Floris R, Isgrò E, et al. Assessment of metabolic brain damage and recovery following mild traumatic brain injury: a multicentre, proton magnetic resonance spectroscopic study in concussed patients. Brain. 2010 Nov; 133(11):3232-42.

45 Narayana PA. White matter changes in patients with mild traumatic brain injury: MRI perspective. Concussion. 2017 Mar; 2(2):CNC35.

46 Lou D, Du Y, Huang D, Cai F, Zhang Y, Li T, et al. Traumatic Brain Injury Alters the Metabolism and Facilitates Alzheimer's Disease in a Murine Model. Mol Neurobiol. 2018 Jun; 55(6):4928-39.

47 Xiao Y, Fu Y, Zhou Y, Xia J, Wang L, Hu C. Proton Magnetic Resonance Spectroscopy ( ${ }^{1} \mathrm{H}$-MRS) Study of Early Traumatic Brain Injury in Rabbits. Med Sci Monit. 2017 May;23: 2365-72.

48 Singh K, Trivedi R, Haridas S, Manda K, Khushu S. Study of neurometabolic and behavioral alterations in rodent model of mild traumatic brain injury: a pilot study. NMR Biomed. 2016 Dec;29(12):1748-58.

49 Zhang P, Zhu S, Zhao M, Dai Y, Zhang L, Ding $S$, et al. Integration of $1 \mathrm{H}$ NMR- and UPLC-Q-TOF/MS-based plasma metabonomics study to identify diffuse axonal injury biomarkers in rat. Brain Res Bull. 2018 Jun; 140:19-27.

50 Li J, Zhao C, Rao JS, Yang FX, Wang ZJ, Lei JF, et al. Structural and metabolic changes in the traumatically injured rat brain: high-resolution in vivo proton magnetic resonance spectroscopy at 7 T. Neuroradiology. 2017 Dec;59(12):1203-12.
51 Riese F, Gietl A, Zölch N, Henning A, O'Gorman R, Kälin AM, et al. Posterior cingulate $\gamma$-aminobutyric acid and glutamate/ glutamine are reduced in amnestic mild cognitive impairment and are unrelated to amyloid deposition and apolipoprotein E genotype. Neurobiol Aging. 2015 Jan;36(1):53-9.

52 Babikian T, Freier MC, Ashwal S, Riggs ML, Burley T, Holshouser BA. MR spectroscopy: predicting long-term neuropsychological outcome following pediatric TBI. J Magn Reson Imaging. 2006 Oct;24(4):801-11.

53 Manley G, Gardner AJ, Schneider KJ, Guskiewicz KM, Bailes J, Cantu RC, et al. A systematic review of potential long-term effects of sport-related concussion. Br J Sports Med. 2017 Jun;51(12):969-77.

54 Gardner AJ, Iverson GL, Wojtowicz M, Levi CR, Kay-Lambkin F, Schofield PW, et al. MR Spectroscopy Findings in Retired Professional Rugby League Players. Int J Sports Med. 2017 Mar;38(3):241-52.

55 Lin AP, Blüml S. Traumatic brain injury and concussion. In: Blüml S, Panigraphy A, editors. MR spectroscopy of pediatric brain disorders. New York: Springer; 2013. p. 67-75.

56 Koerte IK, Lin AP, Muehlmann M, Merugumala S, Liao H, Starr T, et al. Altered Neurochemistry in Former Professional Soccer Players without a History of Concussion. J Neurotrauma. 2015 Sep;32(17):1287-93.

57 Shah RN, Allen JW. Advances in Mild Traumatic Brain Injury Imaging Biomarkers. Curr Radiol Rep. 2017;5(4):5.

58 Ramlackhansingh AF, Brooks DJ, Greenwood RJ, Bose SK, Turkheimer FE, Kinnunen $\mathrm{KM}$, et al. Inflammation after trauma: microglial activation and traumatic brain injury. Ann Neurol. 2011 Sep;70(3):374-83.

59 Lozano D, Gonzales-Portillo GS, Acosta S, de la Pena I, Tajiri N, Kaneko Y, et al. Neuroinflammatory responses to traumatic brain injury: etiology, clinical consequences, and therapeutic opportunities. Neuropsychiatr Dis Treat. 2015 Jan;11:97-106.

60 Loane DJ, Kumar A, Stoica BA, Cabatbat R, Faden AI. Progressive neurodegeneration after experimental brain trauma: association with chronic microglial activation. J Neuropathol Exp Neurol. 2014 Jan;73(1):14-29.

61 Kierans AS, Kirov II, Gonen O, Haemer G, Nisenbaum E, Babb JS, et al. Myoinositol and glutamate complex neurometabolite abnormality after mild traumatic brain injury. $\mathrm{Neu}-$ rology. $2014 \mathrm{Feb} ; 82(6): 521-8$.

62 Tang S, Xu S, Fourney WL, Leiste UH, Proctor JL, Fiskum G, et al. Central Nervous System Changes Induced by Underbody BlastInduced Hyperacceleration: An in Vivo Diffusion Tensor Imaging and Magnetic Resonance Spectroscopy Study. J Neurotrauma. 2017 Jun;34(11):1972-80.
Magnetic Resonance Spectroscopy following Mild Traumatic Brain Injury
Neurodegener Dis 2020;20:2-11 DOI: $10.1159 / 000508098$ 